November $2000 \quad$ • NREL/ CP-520-28579

\title{
Use of Uniformly Distributed Concentrated Sunlight for Highly Accelerated Testing of Coatings
}

Gary Jorgensen, Carl Bingham, David King, Al Lewandowski, Judy Netter, Kent Terwilliger National Renewable Energy Laboratory

Karlis Adamsons DuPont Performance Coatings

Presented at the ACS Conference-Service Life Prediction of Organic Coatings: Methodologies and Metrologies

Monterey, California

November 1999

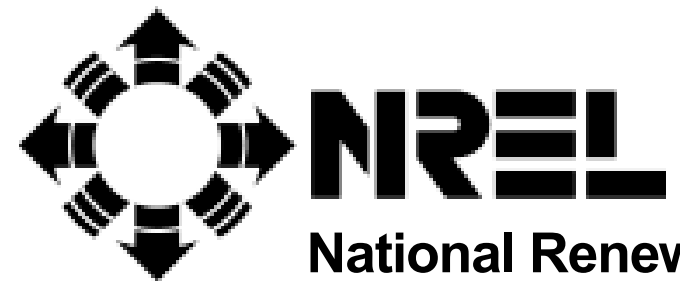

1617 Cole Boulevard

Golden, Colorado 80401-3393

NREL is a U.S. Department of Energy Laboratory

Operated by Midwest Research Institute $\bullet$ Battelle $\bullet$ Bechtel

Contract No. DE-AC36-99-G010337 


\section{NOTICE}

The submitted manuscript has been offered by an employee of the Midwest Research Institute (MRI), a contractor of the US Government under Contract No. DE-AC36-99G010337. Accordingly, the US Government and MRI retain a nonexclusive royalty-free license to publish or reproduce the published form of this contribution, or allow others to do so, for US Government purposes.

This report was prepared as an account of work sponsored by an agency of the United States government. Neither the United States government nor any agency thereof, nor any of their employees, makes any warranty, express or implied, or assumes any legal liability or responsibility for the accuracy, completeness, or usefulness of any information, apparatus, product, or process disclosed, or represents that its use would not infringe privately owned rights. Reference herein to any specific commercial product, process, or service by trade name, trademark, manufacturer, or otherwise does not necessarily constitute or imply its endorsement, recommendation, or favoring by the United States government or any agency thereof. The views and opinions of authors expressed herein do not necessarily state or reflect those of the United States government or any agency thereof.

Available electronically at http://www.doe.gov/bridge

Available for a processing fee to U.S. Department of Energy and its contractors, in paper, from:

U.S. Department of Energy

Office of Scientific and Technical Information

P.O. Box 62

Oak Ridge, TN 37831-0062

phone: 865.576 .8401

fax: 865.576.5728

email: reports@adonis.osti.gov

Available for sale to the public, in paper, from:

U.S. Department of Commerce

National Technical Information Service

5285 Port Royal Road

Springfield, VA 22161

phone: 800.553 .6847

fax: 703.605.6900

email: orders@ntis.fedworld.gov

online ordering: http://www.ntis.gov/ordering.htm

Printed on paper containing at least $50 \%$ wastepaper, including $20 \%$ postconsumer waste 


\title{
Use of Uniformly Distributed Concentrated Sunlight for Highly Accelerated Testing of Coatings
}

\author{
Gary Jorgensen $^{1}$, Carl Bingham ${ }^{1}$, David King ${ }^{1}$, Al Lewandowski ${ }^{1}$, \\ Judy Netter ${ }^{1}$, Kent Terwilliger ${ }^{1}$, and Karlis Adamsons ${ }^{2}$ \\ ${ }^{1}$ National Renewable Energy Laboratory, Golden, CO 80401 \\ ${ }^{2}$ DuPont Performance Coatings, Philadelphia, PA 19146
}

\begin{abstract}
NREL has developed a new ultraviolet (UV) light concentrator that allows material samples to be subjected to uniform intensity levels of 50-100X solar UV at closely controlled sample exposure temperatures. In collaboration with industry, representative coating systems have been exposed without introducing unrealistic degradation mechanisms. Furthermore, correlations have been derived between these highly accelerated test conditions and results obtained at 1-2 suns. Such information is used to predict the degradation of materials in real-world applications. These predictions are compared with measured in-service performance losses to validate the approach. This allows valuable information to be obtained in greatly reduced timeframes, which can provide tremendous competitive advantage in the commercial marketplace.
\end{abstract}

\section{Introduction}

As the performance and durability of new materials improve, the needs of the coatings industry for facilities that provide realistic expectations for in-use exposure testing of their products become increasingly stringent. An urgency exists to greatly extend the service lifetime requirements of decorative and protective coatings for the automotive industry. These businesses simply cannot afford to wait for prolonged periods of time to directly measure product lifetimes or to risk, without substantiating data, providing the warranties demanded by consumers. For example, there is tremendous competitive pressure to increase the present 5-year warranties associated with 19-month design-toproduction cycle times to 10 -year warranties based on a 16-month cycle time. To expedite commercialization, life projections must be made in abbreviated time frames; 
this necessitates using accelerated exposure test (AET) results to allow transformation from life at accelerated stress to life at in-service stress conditions. One of the harshest outdoor stresses these products must withstand is exposure to ultraviolet (UV) radiation contained in terrestrial sunlight.

The National Renewable Energy Laboratory (NREL) has previously demonstrated the ability to expose organic materials (back-metallized polymeric films) to very high levels of solar UV (1). Recently, NREL has developed a new UV concentrator system that is less complicated and more amenable to future commercialization. Using this device, material samples can be exposed to uniform intensity levels of 50-100 times (X) the terrestrial solar UV contained between 290$385 \mathrm{~nm}$. To demonstrate the viability of this process, DuPont provided the characterization of appropriate response variables and a series of representative coating samples for AET at NREL's UV concentrator facility. Relevant environmental stresses were identified and incorporated into models that relate multivariate damage functions to the physical and/or chemical nature of the dominant failure mechanisms experienced by the samples. These models allowed correlations to be made between the service lifetime (SL) at accelerated stress and the SL at in-service stress conditions. AET that simulates reality (i.e., that does not introduce failure mechanisms that are not encountered in actual service) was then used to predict SL.

\section{Experimental}

\section{UV Concentrator}

NREL's UV concentrator is shown schematically in Figure 1. It consists of an array of faceted mirrors that tracks the sun in two axes and redirects sunlight back to a sample exposure chamber attached by three structural support tubes. The concentrator is designed to provide up to $100 \mathrm{X}$ concentration having uniform flux at high UV intensity and low visible (VIS) and near-infrared (NIR) intensity. This is achieved by coating the facets with a custom-designed 37-layer film that uses alternating high and low refractive index materials that results in high UV reflectance and low VIS/NIR reflectance.

The spectral irradiance at the sample exposure plane is presented in Figure 2. The solid line is the concentrated solar intensity as measured by an Ocean Optics SpectraScope fiberoptic spectral radiometer. The dashed curve is an American Society for Testing and Materials (ASTM) direct normal terrestrial air-mass 1.5 solar spectrum (2) multiplied by a factor of 100 . Excellent agreement between the measured spectral irradiance and 100 times the ASTM standard is evident throughout the UV bandwidth (300-400 nm). A steep cutoff at about $475 \mathrm{~nm}$ greatly facilitates thermal

control of samples during exposure. The area between the two curves in the visible and NIR portions of the spectrum represents avoided thermal loading. 
The concentrator uses a close-packed array of 18 hexagonal facets, with their centers located on a near-parabolic surface. Each of the facets has a spherical curvature with a focal length of $150 \mathrm{~cm}$ and an outer diameter (across the vertexes) of $28 \mathrm{~cm}$. The diameter of the effective aperture of the faceted dish is roughly $1.3 \mathrm{~m}$. Individual facets are aimed at a single point in the target plane that is located at a fraction of the nominal focal length. This aiming strategy results in partially concentrated images of the facets and allows a wide range of nearly uniform concentration levels to be achieved by varying the number of facets and target distance. At $100 \mathrm{X}$ concentration the target image is a hexagon with an area of about $87 \mathrm{~cm}^{2}$. This can conveniently accommodate sixteen samples that are each $2-\mathrm{cm} \times 2-\mathrm{cm}$ in size. The various dimensions of the concentrator system can be scaled to allow increased sample exposure areas.

The flux profile was measured using NREL's BEAMCODE characterization system (a product of Coherent Inc.). A solid state array video camera is focused on a near-Lambertian target plate placed at the sample exposure plane. Grey scale images are captured to a computer frame grab board that interfaces with the BEAMCODE software package for flux distribution analysis. Results are shown in Figure 3. The shadows cast by the support tubing on the facets are clearly seen, but the impact on the uniformity is only $4 \%$ in the center and less than $2 \%$ in the shadows. These tubes also provide inlet and outlet cooling water lines and a vacuum line to the sample chamber.

\section{Sample Exposure Chamber}

The sample chamber was constructed from a 2.5 -cm thick block of copper because of its excellent thermal conductivity properties. Details of the chamber are shown schematically in Figure 4. Six $0.64-\mathrm{cm}$ diameter serpentine channels were machined near the top surface of the copper block to allow circulation of cooling water, thereby providing conductive cooling to samples being exposed. A grid of vacuum holes was used to hold the samples in good thermal contact with the copper substrate and to keep the samples in place during exposure while tracking. To accomplish this, 0.64-cm diameter vacuum lines were machined orthogonal to the water cooling channels in the lower half (near the bottom surface) of the copper block, along with a $0.95-\mathrm{cm}$ diameter vacuum manifold channel. A grid of $0.16-\mathrm{cm}$ diameter holes was drilled from the top surface to intersect the vacuum lines to deliver a vacuum pull on the backside of samples to be exposed. The copper block was also machined to accommodate fiber probes to allow real-time monitoring of spectral irradiance experienced by samples being exposed.

The ability of this sample chamber arrangement to control sample temperature during UV exposure at $100 \mathrm{X}$ was demonstrated. While exposed to full power "onsun" conditions (100X), the capacity of chilling water delivered to the chamber was capable of maintaining the surface of the copper block at $12^{\circ} \mathrm{C}$. Test samples had the construction: bilayer paint coating / metal substrate, where the bilayer coating was a clearcoat over either a black or white pigmented paint basecoat and the metal 
substrate was $0.1-\mathrm{cm}$ thick steel. The surface temperature of exposed samples was measured using an infrared (IR) camera (Mikron Instrument Company, Inc., Thermo Tracer TH1100) and a hand held surface thermocouple probe (Omega HPS-HT-K-12SMP-M). The surface probe was used to calibrate the emissivity setting of the IR camera. A value of 0.92 gave good agreement between the two temperature measurements for both black and white painted samples. At $100 \mathrm{X}$ exposure with maximum cooling, surface temperatures ranged between $18^{\circ} \mathrm{C}$ and $26^{\circ} \mathrm{C}$ for white and black samples, respectively. With the chilling water turned off, sample temperatures reached $38^{\circ} \mathrm{C}$ (white) to $52^{\circ} \mathrm{C}$ (black). These maximum temperatures were within the targets/set-points specified by DuPont.

\section{Measurement of UV Exposure}

During exposure testing of candidate coating samples, UV irradiance was continually monitored by two pyranometers: an EKO MS-210W UV-B pyranometer (sensitive to light between 285-315 nm) and an Eppley TUVR pyranometer (sensitive to light between $290-385 \mathrm{~nm}$ ). These instruments were integrally mounted to the UV concentrator so that they tracked the sun during material exposures. They were equipped with occulting tubes to allow only the direct portion of the solar spectrum (i.e., that part of the solar spectrum imaged by the UV concentrator) to be measured. Both pyranometers were periodically calibrated by using an Optronic OL-754 spectral radiometer that measured only the direct solar irradiance. These calibrations indicated agreement with the pyranometers to within $10 \%$. From the one-sun direct irradiance

data and knowledge of the concentrating properties of the UV concentrator, all the information needed to fully characterize the UV exposure of tested samples was provided.

\section{Sample Exposures}

Four sets of samples were provided for accelerated light exposure testing at NREL's UV concentrator facility. DuPont had previously accumulated considerable testing acumen with these sample types exposed in an Atlas Ci-65 WeatherOmeter ${ }^{\mathbb{B}}$ (WOM). This chamber uses an artificial xenon arc light source with borosilicate inner and outer filters. The typical spectral irradiance experienced by the samples is shown in Figure 5; a very close match (i.e., 1X) to an air-mass 1.5 terrestrial solar spectrum is evident throughout the UV region. During Ci-65 exposure, samples were subjected to conditions specified in Society of Automotive Engineers Standard J-1960 (3). A 3hour cycle was used during which the light was on for 2 hours (40 minutes of light; 20 minutes of light with front specimen water spray; and 60 minutes of light) with a sample temperature of $70^{\circ} \mathrm{C}$, and the light was off for one hour with a sample temperature of $38^{\circ} \mathrm{C}$.

The sample sets consisted of 16 types of bilayer paint systems (clear coat/colored basecoat) on steel substrates. Samples were $2-\mathrm{cm}$ x 2-cm in size and $0.1-\mathrm{cm}$ thick. The 
acrylic polyol clearcoats were fortified with various levels of UV absorbers (UVA) and hindered amine light stabilizers (HALS) as indicated in Table I.

Table I. Coating Samples Tested

\begin{tabular}{|c|c|c|c|}
\hline $\begin{array}{l}\text { DuPont } \\
\text { Coating } \\
\text { System }\end{array}$ & Coating Description & $\begin{array}{l}\text { UVA \% } \\
(100 \%= \\
\text { Standard })\end{array}$ & $\begin{array}{l}\text { HALS \% } \\
(100 \%= \\
\text { Standard })\end{array}$ \\
\hline 1.1 & Acrylic Polyol / Melamine Crosslinked & 100 & 100 \\
\hline 1.2 & Acrylic Polyol / Melamine Crosslinked & 100 & 75 \\
\hline 1.3 & Acrylic Polyol / Melamine Crosslinked & 100 & 50 \\
\hline 1.4 & Acrylic Polyol / Melamine Crosslinked & 100 & 25 \\
\hline 5.4 & Acrylic Polyol / Melamine Crosslinked & 100 & 0 \\
\hline 5.3 & Acrylic Polyol / Melamine Crosslinked & 80 & 0 \\
\hline 5.2 & Acrylic Polyol / Melamine Crosslinked & 65 & 0 \\
\hline 5.1 & Acrylic Polyol / Melamine Crosslinked & 16 & 0 \\
\hline 7.3 & $\begin{array}{l}\text { Acrylic Polyol / Melamine \& Silane } \\
\text { Crosslinked }\end{array}$ & 100 & 100 \\
\hline 7.1 & $\begin{array}{l}\text { Acrylic Polyol / Melamine \& Silane } \\
\text { Crosslinked }\end{array}$ & 100 & 0 \\
\hline 7.2 & $\begin{array}{l}\text { Acrylic Polyol / Melamine \& Silane } \\
\text { Crosslinked }\end{array}$ & 0 & 100 \\
\hline 7.4 & $\begin{array}{l}\text { Acrylic Polyol / Melamine \& Silane } \\
\text { Crosslinked }\end{array}$ & 0 & 0 \\
\hline $\begin{array}{l}\text { Comm- } \\
\text { OEM }^{a}\end{array}$ & Acrylic Polyol / Melamine Crosslinked & N/A & N/A \\
\hline $\operatorname{Exp} \# 1^{b}$ & $\begin{array}{l}\text { Acrylic Polyol / Modified Isocyanate } \\
\text { Crosslinked }\end{array}$ & N/A & N/A \\
\hline Comm-Ref $^{c}$ & Acrylic Polyol / Isocyanate Crosslinked & 100 & 100 \\
\hline $\operatorname{Exp} \# 2^{b}$ & Acrylic Polyol / Isocyanate Crosslinked & N/A & N/A \\
\hline
\end{tabular}

${ }^{a}$ Commercial OEM product

${ }^{b}$ Experimental product

${ }^{c}$ Commercial refinish product

At NREL, two experiments were performed, one each at 50 suns and 100 suns UV exposure. A complete set of sixteen samples was exposed each time. Both of these experiments were continued until a cumulative UV-B dose equivalent to 2-3 years outdoor exposure in Miami, FL, was reached. During UV concentrator exposure, humidity was not controlled (ambient levels were $~ 30 \%$ ) and sample temperatures were targeted to be between $40-50^{\circ} \mathrm{C}$; the actual exposure temperatures are given in Table II, along with other details from the accelerated sunlight and Ci-65 tests. To simulate moisture conditions experienced during $\mathrm{Ci}-65$ exposures, samples were exposed in a Q-Panel Lab Products QUV chamber (4) whenever they were not on-sun. The cycle profile was 4 hours with the lights on but blocked (i.e., the samples saw no 
additional light) at $40^{\circ} \mathrm{C}$ and $87 \%$ relative humidity, and 4 hours with the lights off at $40^{\circ} \mathrm{C}$ and $97 \%$ relative humidity (to allow water to condense on the surface of the samples). At the end of each experiment, NREL and DuPont performed various analytical characterizations. These results allowed us to demonstrate a correlation between our 50X and 100X exposures and the $1 \mathrm{X}$ exposures in the Ci- 65 chamber.

Table II. Sample Exposure Conditions

\begin{tabular}{lcccc}
\hline Exposure Chamber & $\begin{array}{c}\text { Sunlight } \\
\text { Intensity }\end{array}$ & $\begin{array}{c}\text { Cumulative } \\
\begin{array}{c}U V-B \\
\left(\mathrm{MJ} / \mathrm{m}^{2}\right)\end{array}\end{array}$ & $\begin{array}{c}\text { Cumulative } \\
\text { Total UV } \\
\left(\mathrm{MJ} / \mathrm{m}^{2}\right)\end{array}$ & $\begin{array}{c}\text { Temperature } \\
\left({ }^{\circ} \mathrm{C}\right)\end{array}$ \\
\hline Ci-65 & $1 \mathrm{X}$ & 16.80 & 372.4 & $70 \pm 2$ \\
UV Concentrator & $50 \mathrm{X}$ & 11.25 & 306.0 & $42 \pm 5$ \\
UV Concentrator & $100 \mathrm{X}$ & 12.77 & 396.5 & $52 \pm 5$ \\
\hline
\end{tabular}

\section{Analysis}

To obtain correlations between in-use and accelerated exposure results, a suitable material-specific damage function model must be found that accurately relates changes in an appropriate response variable to relevant applied environmental stresses. The response variable can be either microscopic (e.g., changes in chemical structure) or macroscopic (e.g., loss of gloss), but ideally should be easily measured and directly related to an important property of the material being tested. For the types of coatings being investigated, a number of useful response variables have been suggested (5).

Coatings are known to be susceptible to degradation caused by cumulative light dosage (D) exposure (6):

$$
D(t) \sim \int_{0}^{t} L(t) d t
$$

where $L(t)$ is the time-dependent incident spectral irradiance, $I(\lambda, t)$, convoluted with the absorption spectra of the material being exposed, $\alpha(\lambda, t)$, and the quantum efficiency of the absorbed photons to propagate reactions that are harmful to the coating, $\phi(\lambda, t)$, integrated over an appropriate bandwidth (defined by $\lambda_{\min }$ and $\lambda_{\max }$ ) throughout which light-induced damage occurs:

$$
\mathrm{L}(\mathrm{t})=\int_{\lambda_{\min }}^{\lambda_{\max }} \mathrm{I}(\lambda, \mathrm{t}) \alpha(\lambda, \mathrm{t}) \phi(\lambda, \mathrm{t}) \mathrm{d} \lambda
$$

In previous work $(1,7)$ with organic materials (back-metallized polymeric films), we have obtained useful results by approximating the absorption spectra and quantum efficiency as constants in eq 2 and defining: 


$$
\mathrm{I}_{\mathrm{UV}}(\mathrm{t})=\int_{\lambda_{\min }}^{\lambda_{\max }} \mathrm{I}(\lambda, \mathrm{t}) \mathrm{d} \lambda
$$

with $\lambda_{\min }=285 \mathrm{~nm}$ and $\lambda_{\max }=315 \mathrm{~nm}$ (for UV-B) or $\lambda_{\min }=290 \mathrm{~nm}$ and $\lambda_{\max }=385 \mathrm{~nm}$ (for total UV). For constant (controlled) irradiance, this leads to an approximate generalized cumulative dosage model in which the loss in performance, $\Delta \mathrm{P}$, (change in response variable) with time is proportional to a power law expression of the ultraviolet irradiance $\mathrm{I}_{\mathrm{UV}}(8,9)$ :

$$
\frac{\Delta \mathrm{P}}{\Delta \mathrm{t}} \sim\left(\mathrm{I}_{\mathrm{UV}}\right)^{\mathrm{n}}
$$

To account for thermal effects, an Arrhenius term can be included and the change in performance after the $i^{\text {th }}$ time interval is:

$$
\Delta \mathrm{P}_{\mathrm{i}}=\mathrm{A}\left(\mathrm{I}_{\mathrm{UV}}\right)^{\mathrm{n}} \Delta \mathrm{t}_{\mathrm{i}} \mathrm{e}^{-\mathrm{E} / \mathrm{kT}}
$$

where $\mathrm{T}$ is the temperature $(\mathrm{K})$ experienced by samples during exposure, $\mathrm{k}$ is Boltzmann's constant, and $\mathrm{E}$ is an activation energy. For constant accelerated stresses, $\mathrm{I}_{\mathrm{UV}}$ and $\mathrm{T}$ are known; this allows eq 5 to be fit to measured values of $\Delta \mathrm{P}_{\mathrm{i}}$ and subsequent determination of the coefficients $\mathrm{A}, \mathrm{E}$, and $\mathrm{n}$. For variable real-world stresses, the time dependent form eq 5 must be used:

$$
\Delta \mathrm{P}(\mathrm{t})=\mathrm{A} \int_{0}^{\mathrm{t}}\left[\mathrm{I}_{U V}(\mathrm{t})\right]^{\mathrm{n}} \mathrm{e}^{-\mathrm{E} / \mathrm{kT}(\mathrm{t})} \mathrm{dt}
$$

Having determined the relevant coefficients from AET's performed at constant stresses, eq 6 can be used to compute a predicted loss in performance after some time $\mathrm{t}$ where the relevant stresses are monitored; these predicted values can then be compared with actual measured values.

\section{Results}

The various coating systems were characterized by transmission mode FTIR analysis as a function of cumulative UV dose exposure. A skiving technique was used in sampling the top $\sim 3-4$ microns of a given specimen. This technique is not readily suitable to obtaining thinner cross sections; attempts often result in shredding. Low temperature sectioning procedures introduce additional complications in terms of sample handling. The skiving approach was used to plane a thin layer of material from the surface of each clearcoat. In previous work, this has proven to be quite acceptable to allow coating degradation mechanisms and kinetics to be studied. Samples were characterized in transmission mode using a Nicolet Magna IR Model 760 spectrophotometer equipped with a Nicolet Nic-Plan IR microscope. Typical results are shown in Figure 6. Spectra were normalized to the same absorbance scale. Although changes in the various bands of interest are small, they can be easily

discerned using Nicolet OMNIC software. The key to this process is to have accurate baseline correction measurements prior to determination of envelope areas. 
Samples were also analyzed with atomic force microscopy (AFM) before and after exposure. The AFM images of the exposed and unexposed samples are quite different; at a $2 \mu \times 2 \mu$ scan the weathered sample appears to have much more micro surface topography than does the unexposed sample. The macro roughness of the coating is preserved, as evidenced by large irregularities and holes in the coating. The visible changes in the topography resulting from exposure are represented by an increase in the root mean square surface roughness from 33 to about 50 angstroms. This increase in roughness is likely representative of surface material that ablates away as the polymer system decomposes as a function of the accelerated weathering process.

The chemical changes, detected with FTIR, that occur in the organic films as a function of accelerated exposure testing are representative of bulk rather than surface photochemical reactions. This is true because the FTIR sampling depth into the coating is on the order of microns, which is much deeper than the surface roughness of the films. Because no analysis technique was used to sample and determine surface chemistry on the order of $5 \mathrm{~nm}$, it is difficult to ascertain the true chemistry precisely at the surface. Although XPS allows the binding energy envelopes for oxygen or carbon (or other appropriate elements) to be monitored in the top $4 \mathrm{~nm}$ of the surface, deconvolution of the XPS spectra and assignment of specific functionality has been difficult. TOF SIMS has been tried with isotope substitution (O-18 for O-16) with some success, but results are difficult to interpret and quantify. The need for improved surface-specific techniques to follow photo-oxidation/hydrolysis reactions remains evident. However, we have found that the FTIR results are consistent with typical changes associated with weathering these materials at much lower acceleration factors.

Based on previous experience with these types of materials $(10,11)$, a specific photo-oxidation index was chosen as the appropriate response variable. This index is calculated from FTIR data as the $[\mathrm{OH}, \mathrm{NH}, \mathrm{COOH}]$ envelope peak area (between $3200-3600 \mathrm{~cm}^{-1}$ ) normalized for thickness by the $[\mathrm{CH}]$ envelope peak area (between $\left.2800-3000 \mathrm{~cm}^{-1}\right) \cdot \Delta \mathrm{P}$ is then defined as the change (difference) between this ratio at any time $\mathrm{t}$ and the unweathered $(\mathrm{t}=0)$ value. Any number of degradation processes may contribute to $\Delta \mathrm{P}$ (photo-oxidation, hydrolysis, etc.). Close inspection of the relevant peaks of the FTIR spectra revealed that hydrolysis did not significantly contribute to $\Delta \mathrm{P}$ for the coatings tested. If hydrolysis was important, a generalized Eyring form of eq 5 could have been used to account for the effect of moisture (7). For samples exposed in the Ci-65 and the UV concentrator, measured values of $\Delta \mathrm{P}_{\mathrm{i}}$ are available for various levels of cumulative dose and sample temperature exposures $\left(70^{\circ} \mathrm{C}\right.$ at $1 \mathrm{X}$ in the $\mathrm{Ci}-65$ and $42^{\circ} \mathrm{C}$ at $50 \mathrm{X}$ and $52^{\circ} \mathrm{C}$ at $100 \mathrm{X}$ in the $\mathrm{UV}$ concentrator). Eq 5 was fit to these data to determine the model coefficients. Representative results for system 5.4 are presented in Figure 7. Here, the predicted change in photooxidation index is plotted vs. measured values for samples subjected to three levels of temperature and light intensity. Additional data at 50X and 100X are desirable but require future longer-term exposures. The validity of the model is indicated by the fact that a straight line having a near-unity slope can represent all of the data. Similar results were obtained for other coating systems and are summarized in Table III. 
Table III. Coefficients Derived for Representative Bilayer Coating Samples

\begin{tabular}{lccc}
\hline DuPont System & $A$ & $n$ & E (kcal/mole-K) \\
\hline 1.2 & 6.513 & 0.667 & 3.878 \\
5.4 & 750.92 & 0.635 & 6.781 \\
7.1 & 370.51 & 0.706 & 6.523 \\
\hline
\end{tabular}

Values of activation energies (E) derived (4-7 kcal/mole-K) are reasonable for photo-thermally driven degradation mechanisms. The values of $n(\sim 0.67)$ imply that exposure to 50-100X light intensities had a net effect of only 15-25X, suggesting that some shielding or rate limiting reactions occur that do not allow all photons to participate in degradation.

To fully substantiate our contention that exposure of coatings at highly accelerated levels of light can produce useful and realistic results, it would be desirable to have measured values of $\Delta \mathrm{P}_{\mathrm{i}}$ for samples of these coatings exposed outdoors where the time dependent stress variables are known. Then, eq 6 could be used to predict $\Delta \mathrm{P}_{\mathrm{i}}$ for comparison with measured data. Unfortunately, such data are not available. However, NREL has a durability testing program that includes outdoor exposure (with carefully monitored radiometric and meteorological conditions) for another organic-based type of material, namely, samples of bulk transparent polymers.

Two types of sheet $(0.32-\mathrm{cm}$ thick) glazing materials have been tested at a variety of outdoor exposure test (OET) sites; these include polyvinyl chloride (PVC) and a UV-stabilized polycarbonate (PC). These materials have also been exposed (12) in an Atlas Ci-5000 WOM having a UV intensity of about $2 \mathrm{X}\left(\right.$ at $60^{\circ} \mathrm{C}$ for both the $\mathrm{PC}$ and $\mathrm{PVC})$ compared to typical outdoor terrestrial levels, and at $50 \mathrm{X}\left(42^{\circ} \mathrm{C}\right.$ for the $\mathrm{PC}$ and $25^{\circ} \mathrm{C}$ for the PVC) and $100 \mathrm{X}\left(48^{\circ} \mathrm{C}\right.$ for the PC and $35^{\circ} \mathrm{C}$ for the PVC) in our UV concentrator. The response variable was chosen to be hemispherical transmittance between $400-500 \mathrm{~nm}$ because, in general, that is the spectral region most sensitive to stress exposure induced loss in performance (Figure 8). The same damage functions expressed in eqs 5 and 6 were assumed. Data from the Ci-5000 and the UV concentrator exposures of the polymer glazings were used to fit eq 5 and to obtain the model coefficients corresponding to these materials; the results are given in Table IV. As with the DuPont coatings, the derived activation energies are not unreasonable. The value of $\mathrm{n}$ for PVC was similar to that found for the DuPont coating systems. For the UV-stabilized PC sample, a value of $n=1$ suggests that exposure of this material follows strict reciprocity even up to $100 \mathrm{X}$; all incident photons fully contribute to degradation reactions that proceed at twice the rate undergone at 50X exposure and 50 times the rate experienced at $2 \mathrm{X}$ exposure.

Table IV. Coefficients Derived for Representative Clear Polymer Sheet Samples

\begin{tabular}{lccc}
\hline \multicolumn{1}{c}{ Polymer Sheet } & $A$ & $n$ & E (kcal/mole-K) \\
\hline Polyvinyl Chloride & 2892 & 0.669 & 8.440 \\
UV-Stabilized Polycarbonate & 5.497 & 1.093 & 6.688 \\
\hline
\end{tabular}


Using the coefficients from Table IV and time-monitored values of sample temperature and UV irradiance, the loss in performance was predicted using eq 6 for both PVC and PC as exposed outdoors in Golden, CO, and Phoenix, AZ. Predicted values were then compared with actual measured data for these materials exposed at these sites. The results are presented in Figure 9. Time-dependent changes in weathering variables produce the irregular shapes of the predicted curves. Excellent agreement is evident between the measured and predicted data, thereby validating the ability to expose samples at very high light levels, our approach to data analysis (using accelerated test results to obtain model coefficients, and then the use of these coefficients to predict time-variable real-world degradation), and the assumed damage function model.

\section{Conclusions}

Correlation between highly accelerated levels (50-100X) of UV light intensity and in-use levels $(\sim 1 \mathrm{X})$ has a number of significant implications. First, these materials can be tested at ultra-accelerated intensities without introducing unrealistic degradation mechanisms. This is an impressive result because the conventional wisdom has been that organic coatings could not be realistically and confidently tested at more than about 10 suns because of difficulties associated with adequately controlling sample temperature. Consequently, very abbreviated testing times can be substituted for long-time exposures at low intensity levels. This will allow much shorter development cycle times for new products; manufacturers will not be forced to wait months or years to ascertain if prospective coating systems will exhibit adequate durability. This will provide a vital competitive advantage to such manufacturers and will result in greatly improved new products.

\section{Acknowledgements}

NREL's UV concentrator was designed, fabricated, installed and tested as part of a cooperative project with NPO Astrophyisca, Moscow, Russia. Development was supported through the U. S. Department of Energy's Initiatives for Proliferation Prevention Program. Samples and useful discussions were provided by Basil Gregorovich at DuPont. AFM characterization was performed at NREL by Helio Moutinho. This paper is dedicated to the memory of David King who was an innovative and dedicated scientist; his insights, enthusiasm, and friendship will be greatly missed by his co-authors and all others who knew him. 


\section{Literature Cited}

1. Jorgensen, G.; Bingham, C.; Netter, J.; Goggin, R.; Lewandowski, A. In Service Life Prediction of Organic Coatings, A Systems Approach; Bauer, D. R. and Martin, J. W., Eds.; ACS Symposium Series 722; American Chemical Society, Oxford University Press: Washington, DC, 1999; pp 170-185.

2. Annual Book of ASTM Standards; Standard E892-87 (Reapproved 1992); American Society for Testing and Materials: Philadelphia, PA, 1993; Vol. 12.02, pp 487-494.

3. Standard SAE J1960; The Society of Automotive Engineers, Inc.: Warrendale, PA, 1989.

4. Annual Book of ASTM Standards; Standard G53-91; American Society for Testing and Materials: Philadelphia, PA, 1993; Vol. 6.01, pp 1045-1050.

5. Bauer, D. R. J. Coatings Tech. 1994, 66, 57-65.

6. Martin, J. W.; Saunders, S. C.; Floyd, F. L.; Weinberg, J. P. Methodologies for Predicting the Service Life of Coatings Systems, NIST Building Science Series 172, National Institute of Standards and Technology: Gaithersburg, MD, 1994.

7. Jorgensen, G.; Kim, H-M.; Wendelin, T.; In Durability Testing of Nonmetallic Materials; Herling, R. J., Ed.; ASTM STP 1294; American Society for Testing and Materials: Scranton, PA, 1996; pp 121-135.

8. Martin, J. W. Durability of Building Materials 1982, 1, 175-194.

9. Carlsson, B. Solar Materials Research and Development; Survey of Service Life Prediction Methods for Materials in Solar Heating and Cooling; International Energy Agency Solar Heating and Cooling Program, Report \# BFR-D-16-1989 (DE90 748556), ISBN 91-540-5063-4; Swedish Council for Building Research: Stockholm, Sweden, 1989; p 27.

10. Adamsons, K.; Lloyd, K.; Stika, K.; Swartzfager, D.; Walls, D.; Wood, B. In Interfacial Aspects of Multicomponent Polymer Materials; Lohse, D. J.; Russell, T. P.; Sperling, L. H., Eds.; Proceedings of an American Chemical Symposium held in Orlando, Florida, August 25-30, 1996; Perseus Books: Cambridge, England, 1998; pp 279-300.

11. Adamsons, K.; Blackman, G.; Gregorovich, B.; Lin, L.; Matheson, R. Progress in Organic Coatings 1998, 34, 64-74.

12. Annual Book of ASTM Standards; Standard G26-92; American Society for Testing and Materials: Philadelphia, PA, 1993; Vol. 6.01, pp 1033-1041.

\section{Separate Figure Caption List}

Figure 1. Schematic of UV concentrator.

Figure 2. Spectral irradiance at sample exposure plane.

Figure 3. Distribution of UV flux at sample exposure plane. 
Figure 4. Schematic of sample chamber.

Figure 5. Spectral irradiance of Ci-65 exposure chamber vs. global air-mass 1.5 terrestrial solar spectrum.

Figure 6. Relative FTIR absorbance of coating system 5.4 as a function of cumulative UV dose.

Figure 7 Measured vs. predicted [OH,NH,COOH] / [CH] for coating system 5.4

Figure 8. Spectral change in transmittance with UV exposure for UV-stabilized PC.

Figure 9. Measured vs. predicted change in hemispherical reflectance between 400$500 \mathrm{~nm}$ for two polymeric materials at two outdoor exposure sites. 




Figure 1. Schematic of UV concentrator.

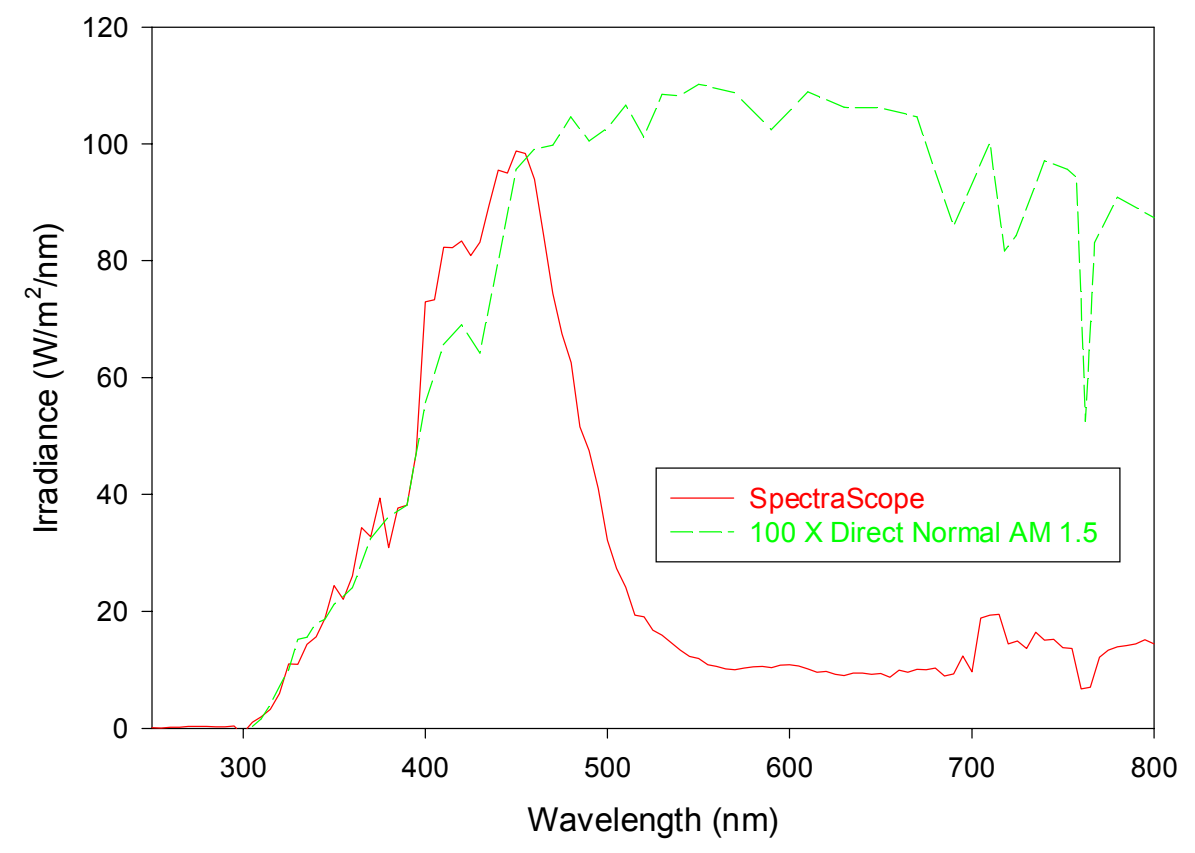

Figure 2. Spectral irradiance at sample exposure plane. 


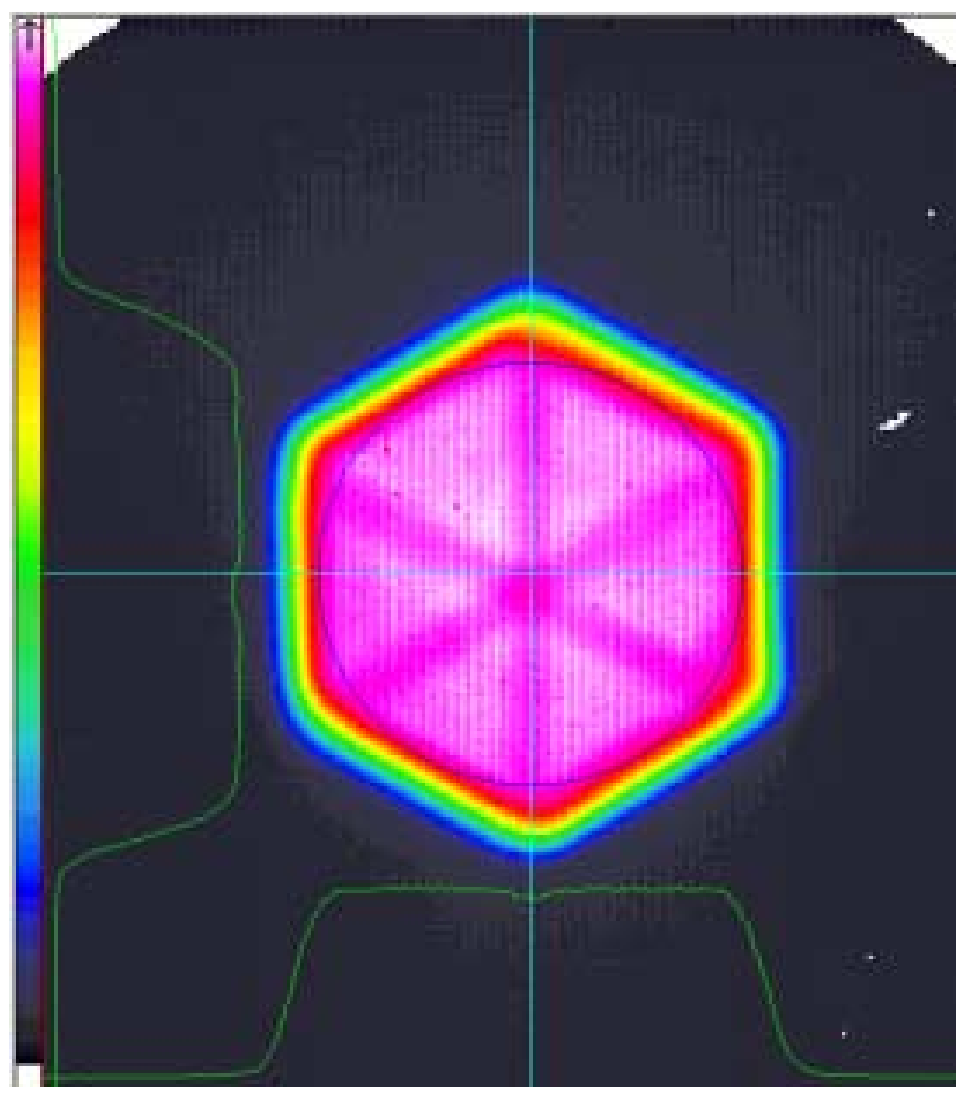

Figure 3. Distribution of UV flux at sample exposure plane.

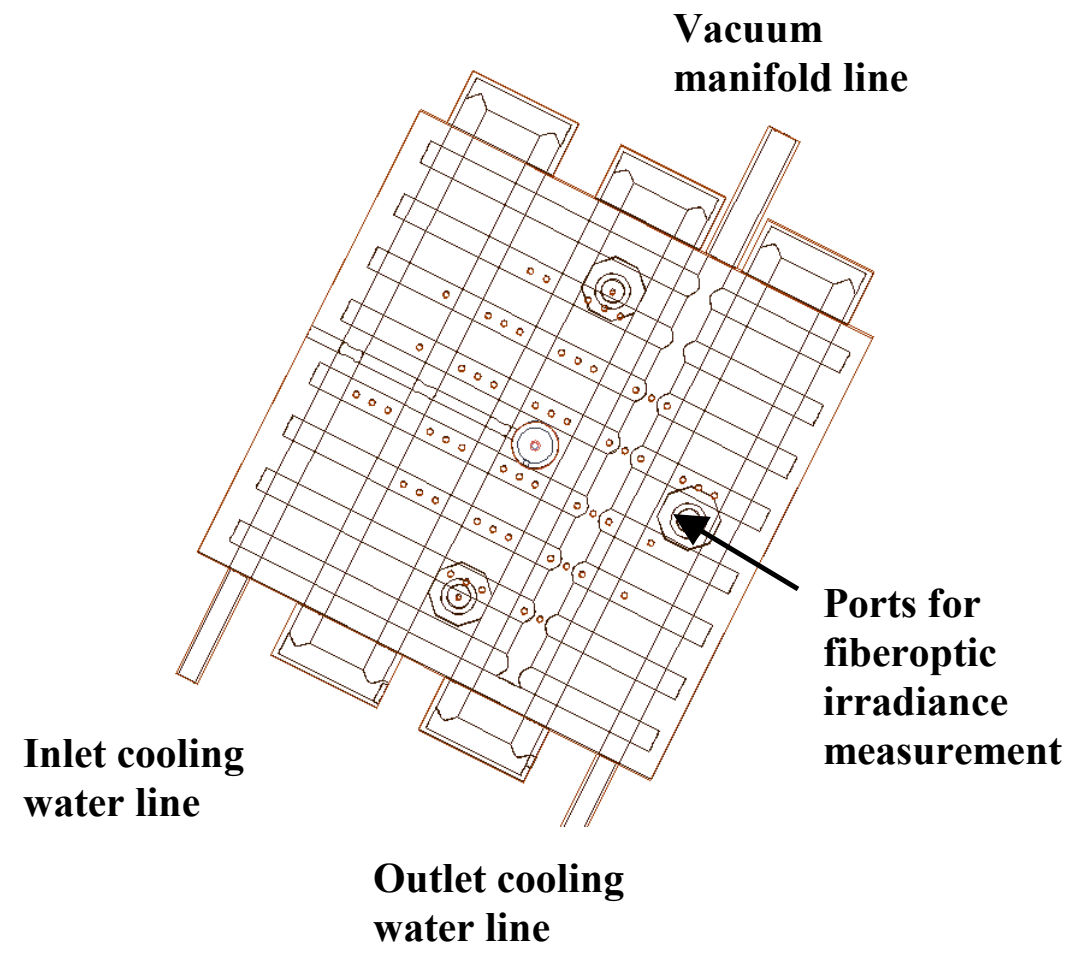

Figure 4. Schematic of sample chamber. 


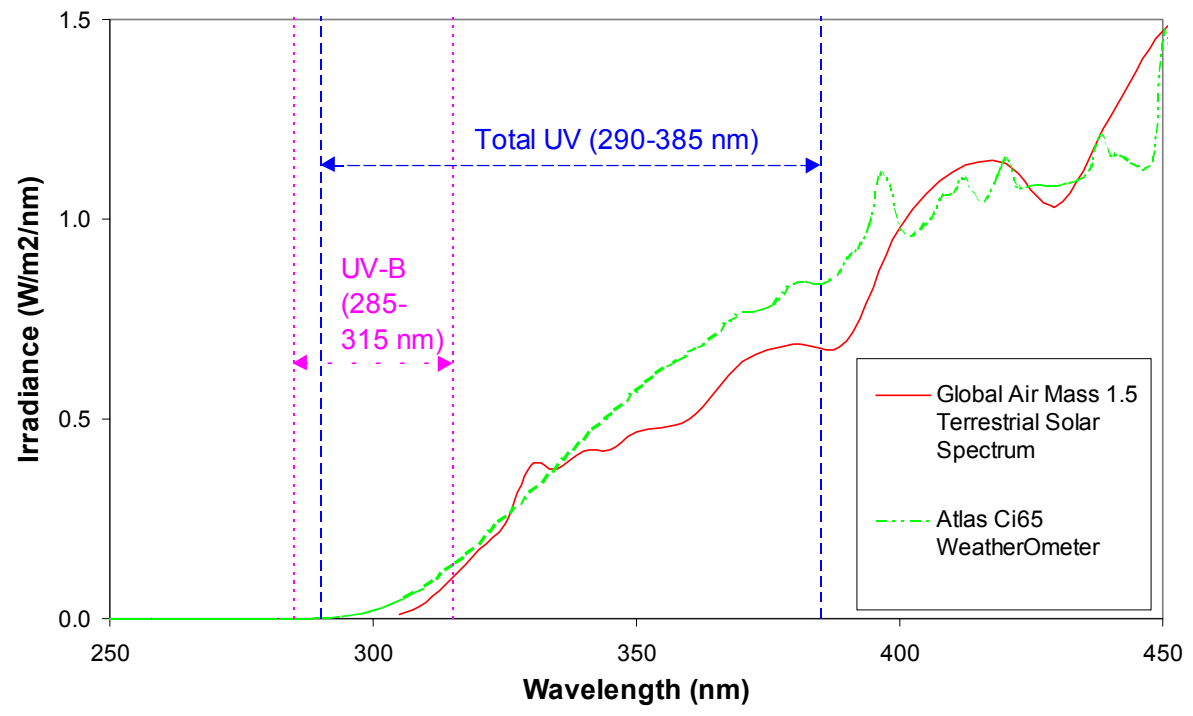

Figure 5. Spectral irradiance of Ci-65 exposure chamber vs. global air-mass 1.5 terrestrial solar spectrum.

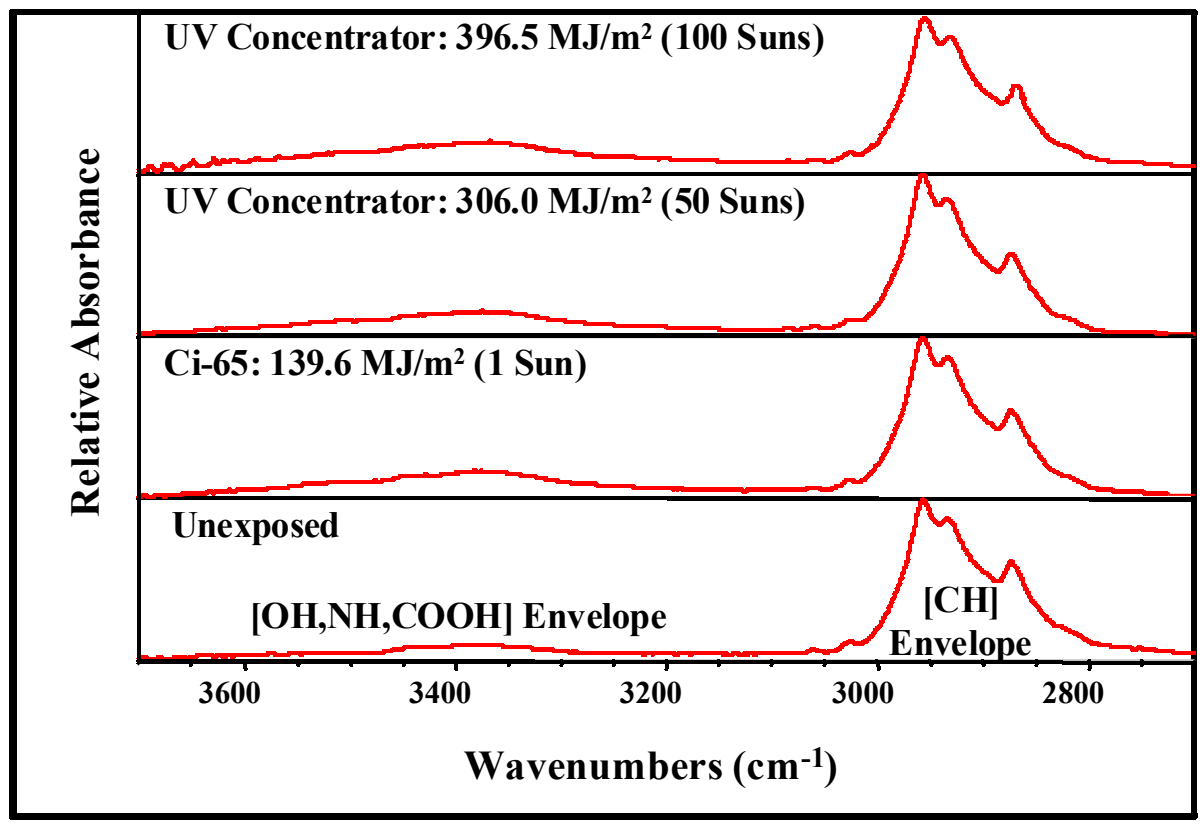

Figure 6. Relative FTIR absorbance of coating system 5.4 as a function of cumulative UV dose. 


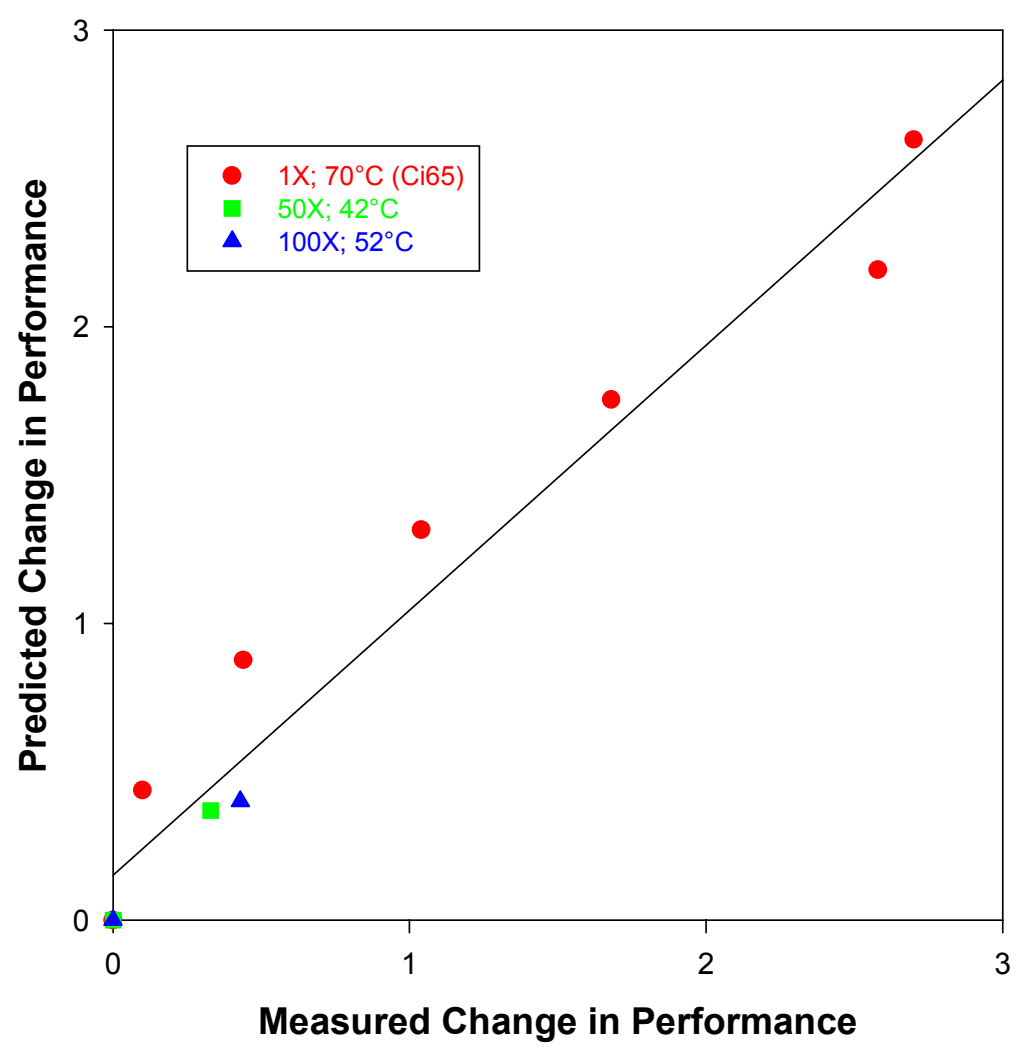

Figure 7 Measured vs. predicted [OH,NH,COOH] / [CH] for coating system 5.4.

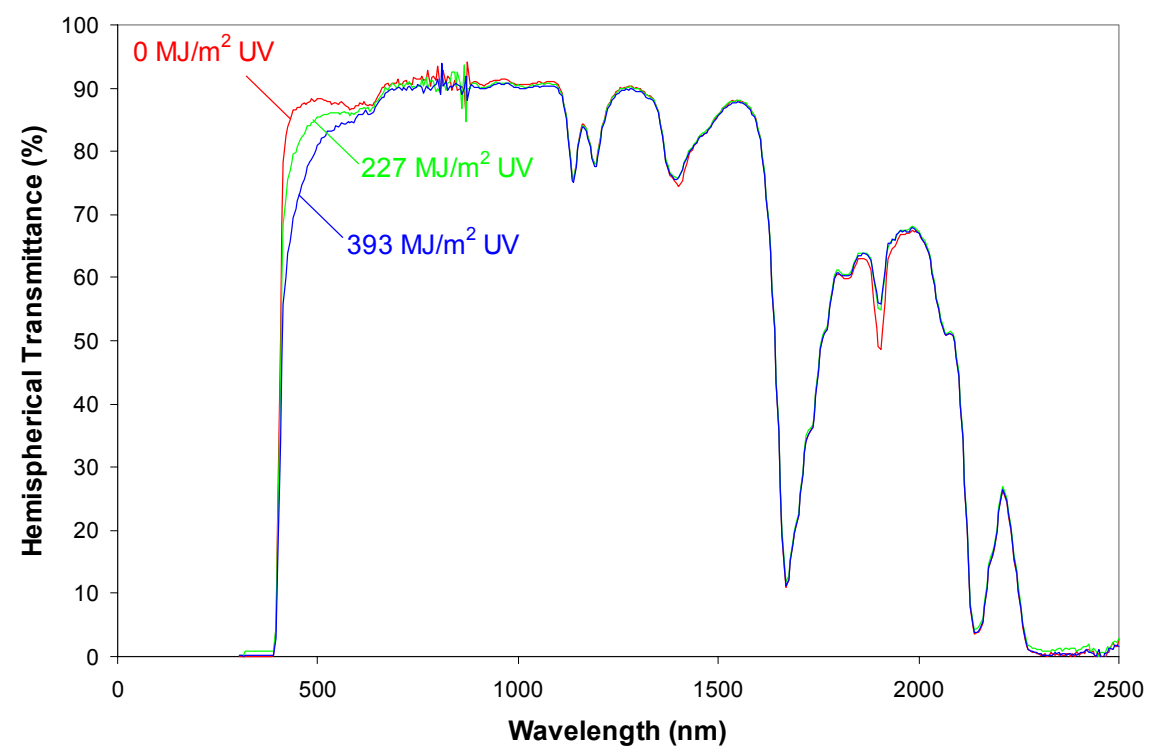

Figure 8. Spectral change in transmittance with UV exposure for UV-stabilized PC. 


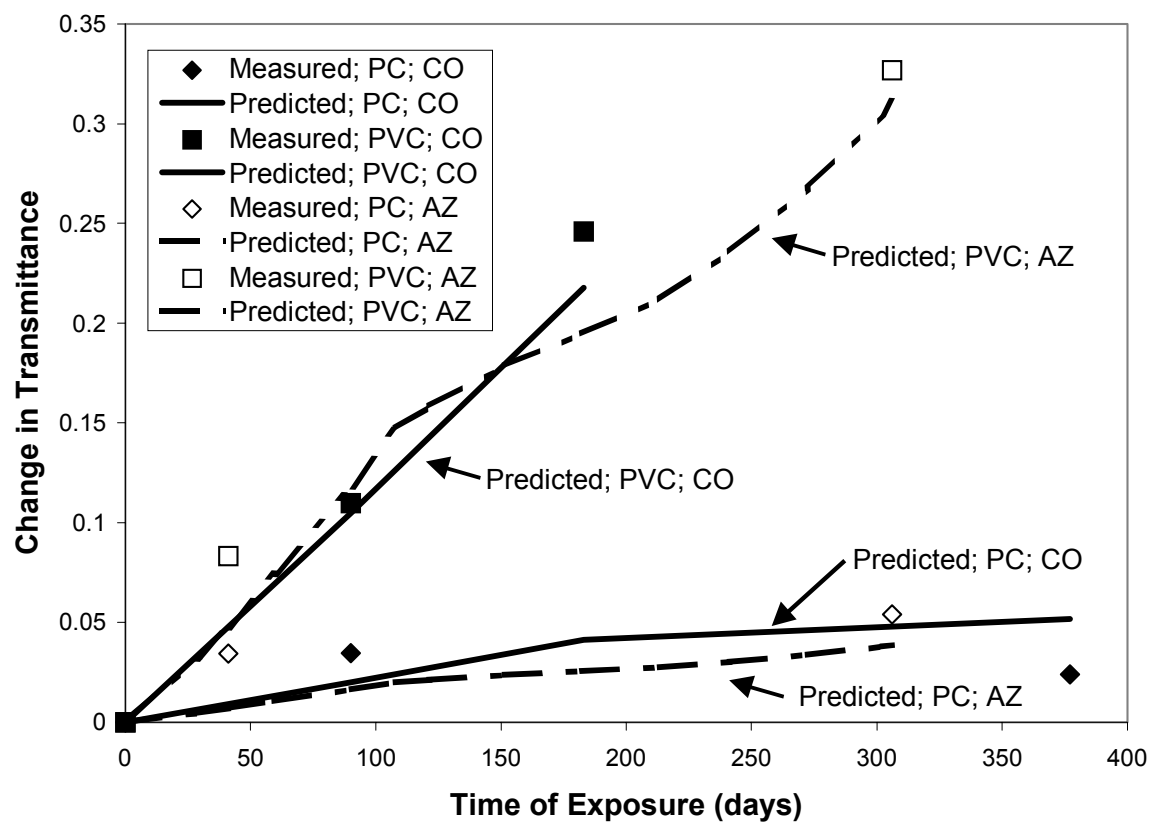

Figure 9. Measured vs. predicted change in hemispherical reflectance between 400-500 $\mathrm{nm}$ for two polymeric materials at two outdoor exposure sites. 


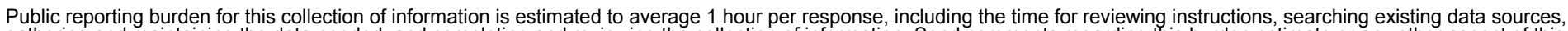

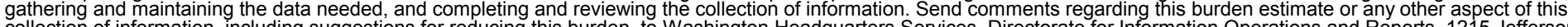

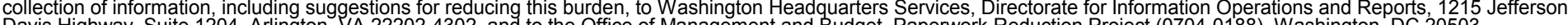
Davis Highway, Suite 1204, Arlington, VA 22202-4302, and to the Office of Management and Budget, Paperwork Reduction Project (0704-0188), Washington, DC 20503.
1. AGENCY USE ONLY (Leave blank)
2. REPORT DATE
November 2000
3. REPORT TYPE AND DATES COVERED
Conference Proceedings, November 1999

4. TITLE AND SUBTITLE

Use of Uniformly Distributed Concentrated Sunlight for Highly Accelerated Testing of Coatings

6. $\operatorname{AUTHOR}(\mathrm{S})$

Gary Jorgensen, Carl Bingham, David King, Al Lewandowski, Judy Netter, Kent Terwilliger, and Karlis Adamsons

7. PERFORMING ORGANIZATION NAME(S) AND ADDRESS(ES)

8. PERFORMING ORGANIZATION REPORT NUMBER

9. SPONSORING/MONITORING AGENCY NAME(S) AND ADDRESS(ES)

National Renewable Energy Laboratory

1617 Cole Blvd.

5. FUNDING NUMBERS

$\mathrm{C}$ :

TA: DO890189

Golden, CO 80401-3393

11. SUPPLEMENTARY NOTES

12a. DISTRIBUTION/AVAILABILITY STATEMENT

12b. DISTRIBUTION CODE

National Technical Information Service

U.S. Department of Commerce

5285 Port Royal Road

Springfield, VA 22161

13. ABSTRACT (Maximum 200 words) NREL has developed a new ultraviolet (UV) light concentrator that allows material samples to be subjected to uniform intensity levels of 50-100X solar UV at closely controlled sample exposure temperatures. In collaboration with industry, representative coating systems have been exposed without introducing unrealistic degradation mechanisms. Furthermore, correlations have been derived between these highly accelerated test conditions and results obtained at 1-2 suns. Such information is used to predict the degradation of materials in real-world applications. These predictions are compared with measured in-service performance losses to validate the approach. This allows valuable information to be obtained in greatly reduced timeframes, which can provide tremendous competitive advantage in the commercial marketplace.

14. SUBJECT TERMS
photovoltatics ; ultraviolet light concentrator ; uniform intersity levels ; ultraviolet radiation ;

back-metallized polymeric films ; faceted mirrors ; thermal conductivity properties ; bilayer paint coating ; irradiance ; accelerated testing

17. SECURITY CLASSIFICATION OF REPORT Unclassified

NSN 7540-01-280-5500

9. SECURITY CLASSIFICATION
OF ABSTRACT
Unclassified

OF THIS PAGE

Unclassified
15. NUMBER OF PAGES

16. PRICE CODE

20. LIMITATION OF ABSTRACT

UL 